\title{
Resultados Do NUTAU'2004
}

\author{
Geraldo G. Serra
}

Para os que ainda não conhecem, NUTAU é a sigla do Núcleo de Pesquisa em Tecnologia da Arquitetura e Urbanismo, da Pró-Reitoria de Pesquisa da USP. O NUTAU foi fundado por um grupo de professores da FAU em 1992 e desde então vem realizando seminários internacionais sobre temas os mais variados, mas sempre ligados à tecnologia da arquitetura e do urbanismo.

Está claro que as atividades do NUTAU não se limitam à organização de eventos, mas incluem, principalmente, a realização de pesquisas em sua área de atuação. Os núcleos de pesquisa da USP, por disposições estatutárias e do Conselho Central de Pesquisa, não recebem recursos do orçamento da

I I6 官

Figura 1: Mesa de abertura, da esquerda para a direita: Prof. Dr. Juan Manuel Borthagaray, diretor do Instituto Superior de Urbanismo da Universidade de Buenos Aires; Prof. Dr. Luis Nunes, pró-reitor de pesquisa da USP; Prof. Dr. Geraldo G. Serra, coordenador científico do NUTAU; Prof. Dr. Ricardo Toledo Silva, diretor da FAUUSP e Prof. Dr. Marcelo de Andrade Roméro, chefe do Departamento de Tecnologia da Arquitetura da FAUUSP

Crédito: Marcos Machado universidade. Dessa forma, as pesquisas dos núcleos devem ser financiadas com recursos obtidos dos interessados nos resultados ou das fundações e instituições de apoio à pesquisa.

Ao longo desses últimos 12 ou 13 anos o NUTAU realizou nove eventos, dos quais oito com caráter internacional. O primeiro desses eventos foi o "First International Symposium on Multimedia for Architecture and Urban Design", realizado em 1992, o qual atraiu cerca de 350 participantes de diversos estados brasileiros e de outros países. Seguiram-se eventos sobre avaliação pós-ocupação, arquitetura de terra e modelos de simulação de ambientes. O sucesso desses eventos levou o NUTAU, em 1995, a tomar a decisão de realizar apenas eventos bienais, com sessões dedicadas, em cada caso, a temas variados da tecnologia da arquitetura e do urbanismo. Em 1996 foi realizado o primeiro desses seminários internacionais que vêm se repetindo a cada dois anos desde então.

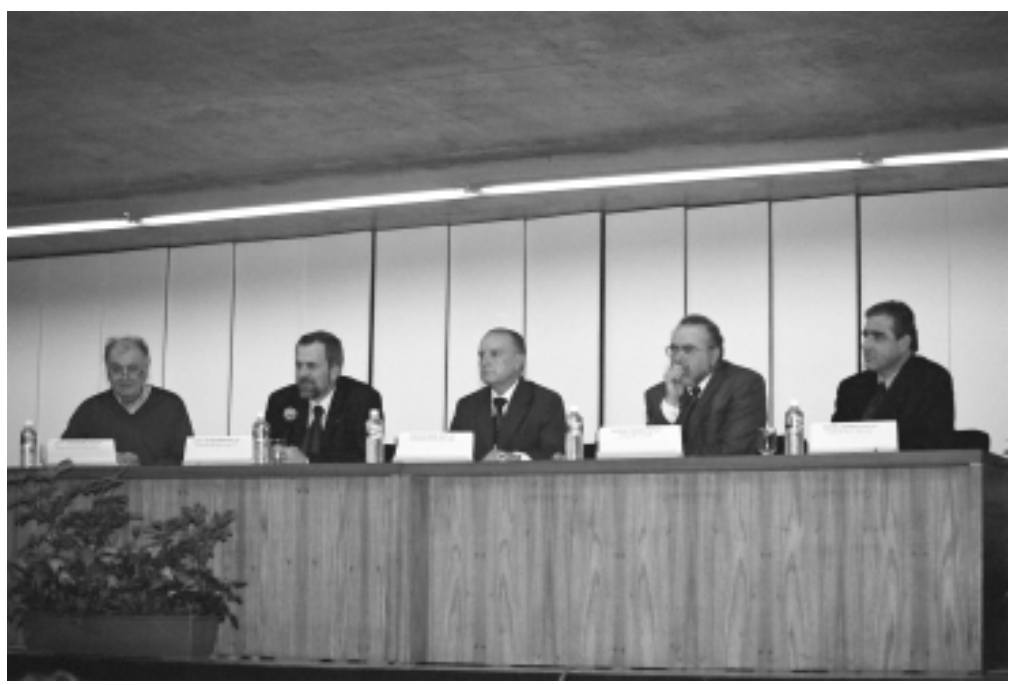


Figura 2: Palestrante convidado, professor Edward Mazria

Universidade do Novo México, EUA

Crédito: Marcos Machado
O NUTAU'2004 adotou como tema central "Demandas Sociais, Inovações Tecnológicas e a Cidade" e foi realizado entre 11 e 15 de outubro, na FAU. Sua estrutura seguiu o modelo adotado desde o início e consiste na realização de quatro sessões sobre subtemas associados ao tema principal e diversos painéis sobre subtemas das referidas sessões. Cria-se, assim, uma "árvore" temática que sempre permite aos diversos pesquisadores encontrarem oportunidades para apresentação de seus trabalhos. Cumpre ressaltar que o pano de fundo das pesquisas e dos temas adotados nos últimos anos tem sido sempre a questão da sustentabilidade do desenvolvimento do ponto de vista da tecnologia da arquitetura, do urbanismo e da construção.

As quatro sessões do NUTAU'2004 foram dedicadas aos temas das megacidades, do conforto ambiental e da economia de energia, da habitação para as populações de baixa renda e do desempenho das edificações em face das inovações tecnológicas. Esses temas se desdobraram em diversos painéis, alguns com vários dias de duração.

Compareceram ao NUTAU'2004 nove especialistas estrangeiros, particularmente convidados para apresentarem trabalhos nas diversas sessões plenárias e também para apoiarem os grupos reunidos em painéis. Vamos passar rapidamente em revista as contribuições aportadas por esses especialistas ao evento.

Edward Mazria, arquiteto, pesquisador e professor visitante na Universidade do Novo México, nos EUA, pronunciou a palestra de abertura do seminário sobre a produção de gás carbônico $\left(\mathrm{CO}_{2}\right)$ pelas construções e pelos edifícios.

Realmente, a revista Metrópolis, dedicada à sustentabilidade das megacidades, havia publicado trabalhos, inclusive de Mazria, sobre a questão da produção de dióxido de carbono pelas edificações, que, no caso dos países em latitudes mais altas, tende a ser maior, diante do aquecimento de ambientes utilizando caldeiras a queimarem petróleo. Além disso, nos EUA e em outros países também é comum

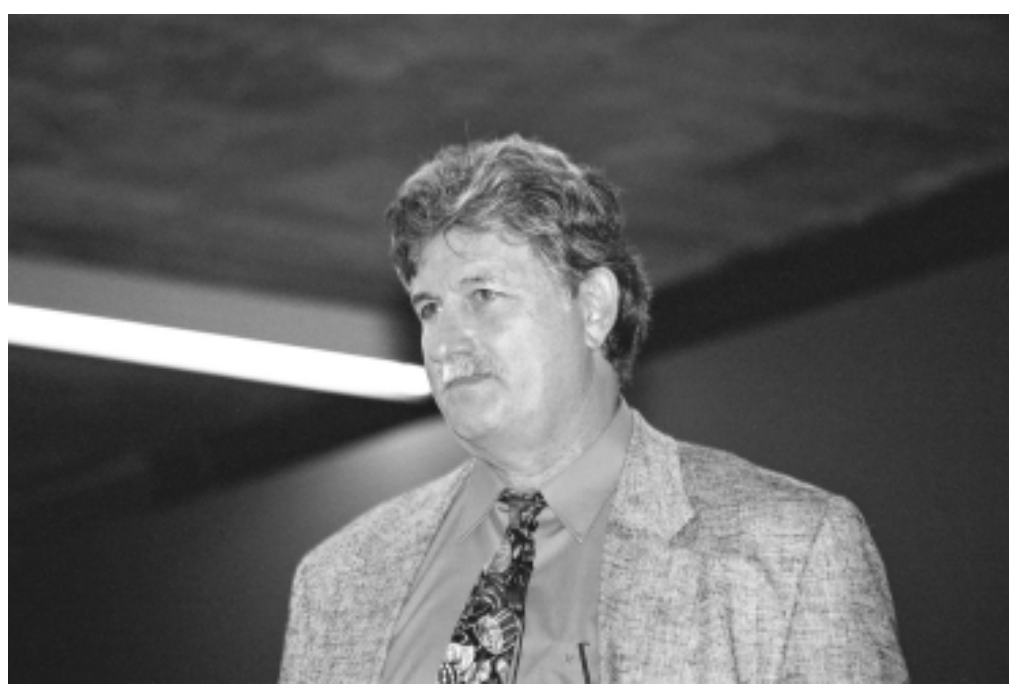


a utilização de petróleo para a produção de energia elétrica. Embora entre nós haja maior preocupação com o trânsito urbano, Mazria mostrou que a maior parte do gás carbônico naqueles países provém dos edifícios e não dos automóveis.

Na sessão dedicada às megacidades o professor Rui Godinho, ex-viceprefeito de Lisboa e atual diretor da Valorsul, empresa dedicada ao processamento dos resíduos sólidos daquela capital, apresentou uma visão positiva das cidades como solução para o desenvolvimento sustentável. Realmente, muitos pesquisadores têm mostrado que a concentração dos problemas de sustentabilidade nas megacidades não faz delas a causa desses problemas, que continuariam a existir, mesmo que a população estivesse menos aglomerada, mas tornam mais fácil a solução. Na mesma sessão, o professor Juan Manuel Borthagaray, diretor do Instituto Superior de Urbanismo da Universidade de Buenos Aires, mostrou a importância do Projeto Puerto Madero do ponto de vista funcional e programático para o desenvolvimento da cidade de Buenos Aires, inclusive pela preservação de antigas construções e do próprio porto. Na mesma ocasião, tive a oportunidade de apresentar meu trabalho sobre o papel das megacidades no processo de globalização, particularmente, na visão da migração.

Na sessão dedicada à problemática do conforto ambiental e da conservação de energia, Koen Steemers, Klaus Bode e Susannah Hagan, os três do Reino Unido, apresentaram abordagens atualizadas sobre a matéria. 0 trabalho de Steemers trata de uma questão muito difícil: o conforto em espaços urbanos abertos, assunto que vem sendo estudado entre nós pela professora Denise Duarte. Klaus Bode mostrou vários exemplos de projetos preocupados com a questão da sustentabilidade. Hagan destaca a importância da inovação tecnológica na produção de uma arquitetura sustentável, inclusive como abordagem dos projetistas.

O tema da habitação social foi discutido sob a presidência da professora Maria Ruth Amaral de Sampaio pelo professor Raúl Fernández Wagner, da Universidade Sarmiento, de Buenos Aires, e pela professora Ada Esther Portero Ricol, diretora da Faculdade de Arquitetura da Universidade José Antonio Echeverría, de Havana, Cuba. Wagner apresentou a necessidade de revisão crítica das políticas habitacionais na América Latina, sob a ótica argentina atual. Ricol apresentou a experiência realizada no município Cerro, do ponto de vista de seus resultados ambientais e de contextualização urbana.

Na sessão dedicada à avaliação de desempenho e inovação tecnológica o doutor arquiteto António Baptista Coelho, do Laboratório Nacional de Engenharia Civil, de Lisboa, apresentou a evolução da habitação social em Portugal, com a perspectiva dos 15 anos do Prêmio do Instituto Nacional da Habitação. Esse prêmio é distribuído todos os anos para os melhores conjuntos habitacionais construídos em Portugal, e a experiência do doutor Baptista Coelho, nessas premiações, confere-Ihe um enfoque privilegiado e uma visão ampla sobre o assunto. Nessa mesma ocasião Edward Mazria apresentou alguns exemplos de sua produção arquitetônica nos EUA do ponto de vista da inovação tecnológica, 
Figura 3: Visita ao Mercado Municipal de São Paulo Crédito: Denise Duarte visando a uma arquitetura sustentável. Da mesma forma, apresentei o projeto do novo Instituto de Psiquiatria da USP, ao qual tenho me dedicado nos últimos anos e cuja obra pôde ser visitada pelos participantes do seminário, destacando a aplicação da metodologia de programação arquitetônica em um edifício com funções muito especiais.

Aconteceram, ainda, visitas técnicas às intervenções urbanas realizadas ou em realização no mercado municipal, na Pinacoteca do Estado, na Estação da Luz, no edifício Copan, em processo de avaliação e renovação e às obras do Instituto de Psiquiatria do Hospital das Clínicas. Essas visitas permitiram ilustrar, na prática, os temas em discussão no seminário.

Além das sessões plenárias e das visitas técnicas foram realizados painéis sobre os seguintes temas:

- Avaliação de desempenho e avaliação pós-ocupação

- Conforto ambiental e conservação de energia

- Globalização, urbanização e desenho urbano

- Habitação de interesse social

- Instalações hospitalares e assistenciais

- Segurança contra incêndio

- Invenção, descoberta e inovação

- Resíduos sólidos urbanos

Como resultado desses painéis, 233 trabalhos foram incluídos nos anais, a maior parte dos quais apresentada oralmente e discutida. Note-se que o número de resumos encaminhados à Comissão Científica do evento foi muito maior, sendo os trabalhos mencionados acima aqueles por essa selecionados para apresentação ou apenas para publicação nos anais.

O seminário contou com mais de 400 participantes, limitados pelas dimensões do auditório da FAU, assim como o número de painéis simultâneos é limitado pelo número de salas das quais podemos dispor.

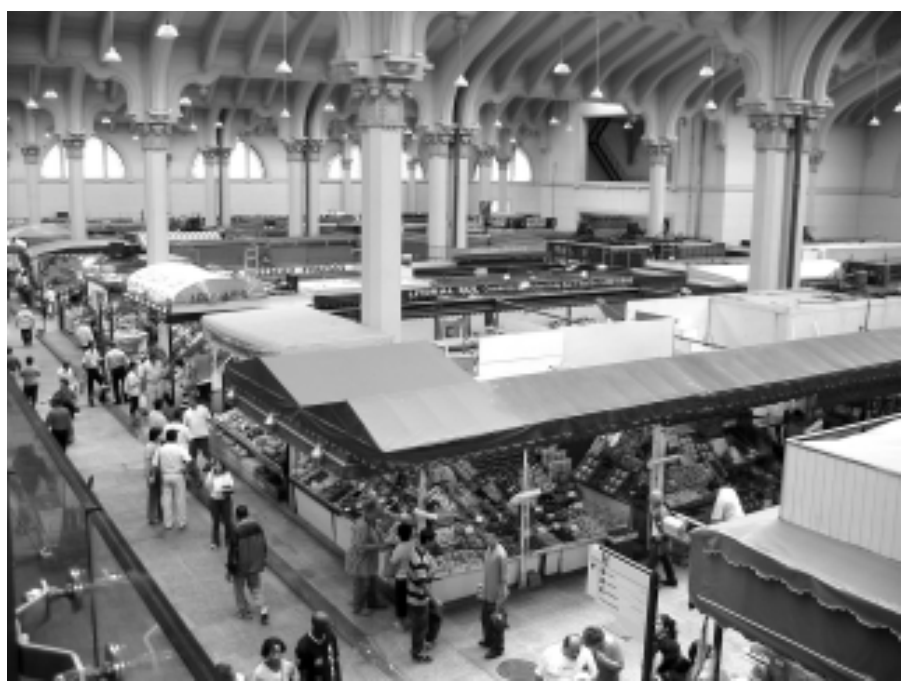


Como resumir e avaliar os resultados de todo esse esforço? Podemos responder a essa questão do ponto de vista científico, da difusão de conhecimentos e da atualização acadêmica e mesmo didática.

Na visão científica pode-se concluir que a sustentabilidade da arquitetura, da construção e da cidade é, hoje, a preocupação central dos pesquisadores. Sustentabilidade aqui não é meramente uma vaga preocupação ideológica com o meio ambiente, mas um critério de planejamento, projeto, construção e operação dos edifícios e de suas aglomerações que garanta a continuidade do processo de desenvolvimento urbano. Ela se expressa pela economia de meios tanto materiais como energéticos, pela ênfase na reciclagem de edifícios e dos espaços urbanos, pela consciência dos aspectos sociais envolvidos, pela importância conferida à segurança e à economia, e mesmo pela preocupação com o que podemos chamar da estética da sustentabilidade, ou seja, com os resultados formais implicados.

Como difusão de conhecimentos e atualização acadêmica a importância dos seminários do NUTAU é sentida há muitos anos e manifestada, seguidas vezes, por seus participantes. Em primeiro lugar, cabe verificar que eles vêm de todo o Brasil, de diversos países latino-americanos e de Portugal, e não apenas da cidade ou do estado de São Paulo. Já tivemos, nos seminários do NUTAU, participantes de países tão distantes como a China, o Japão e a Nova Zelândia, além de inúmeros países europeus e americanos. O seminário cria condições não apenas de ver e ouvir especialistas de diversos países apresentando seus trabalhos, mas de conversar com eles e discutir os problemas que cada participante aponta em sua própria cidade ou região. Mais do que isso, ele é um espaço em que os participantes podem, em muitos casos pela primeira vez, apresentar seus trabalhos e vê-los discutidos e publicados. Ora, considerando que a maior parte dos participantes é formada por pós-graduandos, mestrandos e doutorandos de múltiplas faculdades e instituições, pode-se aquilatar a importância da interação com especialistas e colegas.

Finalmente, mas não menos importante, é o fato de muitos participantes serem docentes e sua participação na reunião, certamente, terá rebatimentos em suas escolas e em suas aulas.

Nós, do NUTAU, sentimos tudo isso, mas procuramos sempre ouvir a opinião de nossos colegas e pesquisadores de outras instituições, de forma a corrigir quaisquer conclusões apressadas provenientes de nosso ponto de vista. $\mathrm{Na}$ verdade, em todos os eventos ouvimos sempre palavras de incentivo e de satisfação com os resultados. Acreditamos, por isso, que os seminários internacionais do NUTAU, já tradicionais no cenário acadêmico brasileiro e até em outros países, constituem-se em uma real contribuição que a USP e a FAU concedem ao desenvolvimento científico.

Geraldo G. Serra

Professor Doutor da FAUUSP e coordenador científico do NUTAU. 